International Journal of Behavioral Research \& Psychology (IJBRP)

ISSN 2332-3000

\title{
Analyzing Compliance Rate of Intended Andimplemented Curriculum Of Research And Thinking Textbook In Sixth Elementary Grade In Maidenly Schools Of Urmia City In Iran.
}

Tayefeh E, Sheikhzadeh $\mathrm{M}^{*}$

Research Article

${ }^{1}$ Department of education, Urmia branch, Islamic Azad University, Urmia, Iran.

\section{Abstract}

This research tries to present a general image of compliance and consistency rate of implemented and intended curriculum in research and thinking textbook of elementary sixth grade in Iran according to its four major elements. Research is descriptive- survey type. Statistical population contains all elementary sixth grade teachers of maidenly schools in Urmia city. Research's statistical samples are 102 elementary sixth grade teachers that are selected as simple random- classified sampling. Reaching to intend curriculum was realized through analysis of thinking and research textbook's content (textbook's all sentences analysis unit). To reach implemented curriculum a researcher made questionnaire was used that contains 43 answer packs and is adjusted based on Likret scale. Research results show that in terms of intended and implemented curriculum of thinking and research textbook, knowledge goals are higher than average. In terms of intended and implemented curriculum, attitudinal goals are higher than knowledge goals average. According to teachers' statement in terms of intended and implemented curriculum, skill goals are reported higher than 4 . Also results show that attention is not paid to all curriculum components in implemented curriculum namely from teachers' view point intended curriculum of elementary sixth grade thinking and research textbook in maidenly schools of Urmia city is not available about all components of curriculum in specified notes performing.

Key words: Intended Curriculum; Implemented Curriculum; Textbook; Elementary Sixth Grade; Curriculum Components.

\section{*Corresponding Author:}

Mostafa Sheikhzadeh,

Department of education,

Urmia branch, Islamic Azad University, Urmia, Iran.

E-mail:m.sheikhzade@gmail.com

Received: January 13, 2014

Accepted: January 22, 2014

Published: January 24, 2014

Citation: Tayefeh E, Sheikhzadeh $\mathrm{M}^{*}$ (2014) Analyzing Compliance Rate of Intended and Implemented Curriculum of Research and Thinking Textbook in Sixth Elementary Grade in Maidenly Schools of Urmia City in Iran. Int J Behav Res Psychol. 2(1), 15-17. doi: http://dx.doi. org/10.19070/2332-3000-140004

Copyright: Mostafa Sheikhzadeh ${ }^{\circ} 2014$. This is an open-access article distributed under the terms of the Creative Commons Attribution License, which permits unrestricted use, distribution and reproduction in any medium, provided the original author and source are credited.

\section{Introduction}

With the development of review and planning knowledge in principles of education purposes and goals globally, important changes have been done in training patterns and methods and students evaluation (Shabani, 2008, P191). In curriculum design, production and performing process usually three curriculum types namely intended, implemented and experiences are used that intended curriculum deals with ideals, goals, content, learning- teaching methods and predicted material in curriculum which are prescribed by curriculum planners in an educational system. Implemented curriculum is a set of learning- teaching activities and proceedings that are implemented based on intended curriculum and teachers' comprehension in classrooms' real environments (Fathi and Ejargah, 2002, P78).
Curriculum contains four fundamental components: 1- general, slight and objective goals, 2- designs, 3- implementation (educating), 4- evaluation (Taghipoor, Zahir 1994, P42). Elementary sixth grade thinking and research textbook is recently compiled in Iran and this research seeks to answer to this important question that is there any consistency and compliance between two intended and implemented curriculum in terms of four curriculum components?

\section{Materials and Methods}

Considering that this research tries to present a general image of compliance and consistency rate of implemented and intended curriculum in research and thinking textbook of elementary sixth grade, method of research is descriptive in survey type. Statistical population is research and thinking textbook of elementary sixth grade that is compiled and provided for academic year 20122013. Also statistical population contains all elementary sixth grade teachers that were teaching in maidenly schools in academic year 2012- 2013. Sample volume is equal to 102 ones. Implemented curriculum tool contains a questionnaire to conduct add a comment from elementary sixth grade teachers that contains 43 answer pack questions based on Likret scale.

\section{Results}

Main question No. 1: is there a significant difference between goal of implemented and intended curriculum in elementary sixth grade thinking and research textbook?

Based on Kolmogorov-Smirnov test result one sample T- test is used to analyze this question: 
Results of this test show that significant level is lower than 0.05 and there is significant relation. This means that teachers' view point about goal component is consistent with intended curriculum.

Main question No. 2: is there a significant difference between content of implemented and intended curriculum in elementary sixth grade thinking and research textbook?

Results of this test show that significant level is lower than 0.05 and there is significant relation. This means that teachers' view point about content component is consistent with intended curriculum.
Main question No. 3: is there a significant difference between teaching methods of implemented and intended curriculum in elementary sixth grade thinking and research textbook?

Results of this test show that significant level is lower than 0.05 and there is significant relation. This means that teachers' view point about teaching methods component is consistent with intended curriculum.

Main question No. 4: is there a significant difference between evaluation of implemented and intended curriculum in elementary sixth grade thinking and research textbook?

Schedule 1. one sample T- test results of main question number 1

\begin{tabular}{|c|c|c|c|c|c|c|}
\hline & \multicolumn{3}{|c|}{ Average analysis/difference level analysis $=2.5$} \\
\cline { 2 - 7 } & $\mathrm{T}$ & Freedom degree & Significant level two ranges & Average difference & \multicolumn{3}{|c|}{$\begin{array}{c}90 \% \text { confidence interval } \\
\text { difference }\end{array}$} \\
\cline { 5 - 8 } & & & & 1.77052 & 1.6721 & Lower \\
\hline Goal component & 35.683 & 101 & .000 & 1.8689 \\
\hline
\end{tabular}

Schedule 2. K- square test results of main question number 2

\begin{tabular}{|c|c|}
\hline & Content component \\
\hline K- square & $74.137^{\mathrm{c}}$ \\
\hline Freedom degree & 12 \\
\hline Significant level & .000 \\
\hline
\end{tabular}

Schedule 3. K- square test results of main question number 3

\begin{tabular}{|c|c|}
\hline & Method component \\
\hline K- square & $34.745^{\mathrm{d}}$ \\
\hline Freedom degree & 10 \\
\hline Significant level & .000 \\
\hline
\end{tabular}

Schedule 4. K- square test results of main question number 4

\begin{tabular}{|c|c|}
\hline & Evaluation component \\
\hline K- square & $37.176^{\mathrm{a}}$ \\
\hline Freedom degree & 13 \\
\hline Significant level & .000 \\
\hline
\end{tabular}

Results of this test show that significant level is lower than 0.05 and there is significant relation. This means that teachers' view point about evaluation component is consistent with intended curriculum.

\section{Discussion and Conclusion}

Akhlaghi (2004) in his master's thesis under the name of analyzing social studies course's intended and implemented curriculum's consistency and compliance rate in secondary school first grade for boys in Tehran in academic year 2004- 2005 concluded that knowledge and attitudinal goals are followed very consistent with intended curriculum. According to teachers' statements skill goals are very consistent with intended curriculum. Research results are very consistent with results of this research. Gholizade (2012) in a research under the name of analyzing intended and implemented curriculum of art course in elementary stage of Makoo Township from teachers view point, analyzed the intended and implemented curriculum of art course and results showed that there is significant difference between implemented and intended curriculum of art course in terms of cognitive, emotional, social and educational dimensions that results of his research are consistent with this research.

Also Aziz (2007) in his master's thesis under the name of analyzing Religion and Life course's intended and implemented curriculum's consistency and compliance rate in secondary school third grade for boys in Shiraz in academic year 2006- 2007 concluded that in terms of Religion and Life textbook's goals all of students were reached to predetermined goals. Nazari (2011) believes that schools' religious textbooks are not efficient enough to train goals in emotional or attitudinal domains and mostly their look is toward cognitive goals domain and there is need to renovation of 
religious textbooks in terms of emotional domain's goals induction. Also courses such as literature, social educations, and history and... that sometimes contain religious instructions should be renovated. Furthermore teaching methods of teachers in religious domain should be revised basically and emotional goals induction methods should be considered in their teaching methods that it is somehow consistent with findings of this research that from experts' and teachers' view point noticing rate to curriculum components is not high and should be considered by authors and teachers.

According to findings of Rahbarinejad (1998) that has analyzed science textbook of elementsary fifth grade it is specified that in presenting textbook's concept it is not adequately noticed to necessary prerequisites in order to start the topic. Due to lack of clarity or incompleteness, some of images in textbook couldn't play their roll well and also in some cases they caused students misunderstanding. It should be said that in this research textbook's slight parts are not considered separately. in Maidenly Schools of Urmia City in Iran. Int J Behav Res Psychol. 2(1), 15-17.

\section{References}

[1]. Akhlaghi, Morteza (2005). Analyzing consistency and compliance rate of implemented and intended curriculum of social studies course in first grade of secondary schools for boys, Tehran, academic year 2004- 2005, master's thesis, education and psychology college of Tehran.

[2]. Ebrahimi, Ali (1998). Curriculum planning (new approaches). Tehran: Fekr e No publications.

[3]. Taghipoor, Zahir (1994). An introduction to curriculum and education planning. Tehran, Agah publications.

[4]. Shabani, Hasan (1998). Educating and training skills ( teaching methods and skills), twenty- second edition, Tehran: Samt publications.

[5]. Azizi, Habibollah (2007). Analyzing consistency and compliance rate of implemented and intended curriculum of life and religion course in first grade of secondary schools for boys, Shiraz, academic year 2006- 2007, master's thesis, education and psychology college of Tehran.

[6]. Fathi and Ejargah, Koorosh (2002). Curriculum planning, Tehran: Iran Zamin publications.

[7]. Gholizadeh, Heydarali (2002). Analyzing intended and implemented curriculum of art course in elementary stage of Makoo Township from teachers' viewpoint, Islamic Azad University, Urmia baranch.

[8]. John Miller (2004). Learning theories, translation of Mahmood Mehrmohamadi (2000). Tehran, organization of studying and compiling human science books for universities, Samt publications. 